\title{
Ageing Populations: Economic Challenges and Policy Implications
}

\author{
Bhavya Visal
}

\begin{abstract}
This paper analyses the economic challenges presented due to the recent phenomenon of a rapidly ageing population and recommends suitable policies, while also highlighting the case studies of Japan and Italy - countries with the highest proportion of their population aged above 65 in the world.
\end{abstract}

Index Terms - Ageing population, economics, policies.

\section{INTRODUCTION}

For the first time in history, in 2018, the number of people aged 65 or above outnumbered children under five years of age across the world [1], and by 2050, 1 in 6 people globally will be over the age of 65 [1].

Population ageing is unarguably one of the most significant social transformations in the twenty-first century. More severe in advanced, industrialized nations, this phenomenon is driven by key demographic factors: increased longevity and reductions in fertility [2].

\section{Costly and inadequate \\ In advanced economies, pension spending as a percent of GDP is rising while pension expenditure per elderly person as a percent of income per capita (the economic replacement rate) soon will fall.
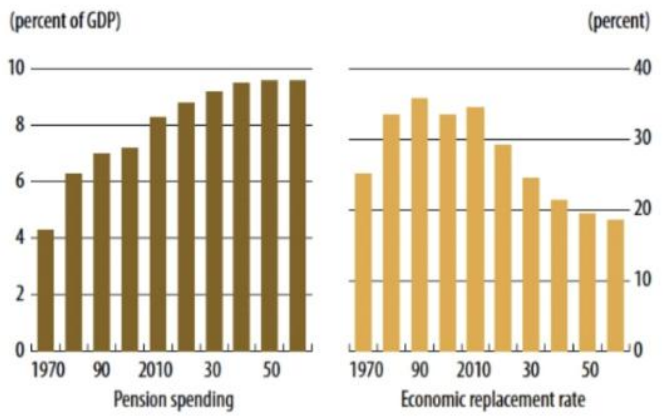 \\ Sources: Organisation for Economic Co-operation and Development; United Nations; and IMF staff calculations. \\ Note: The economic replacement rate is average pension spending per individual 65 and older divided by GDP per capita for those ages 15-64. Data after 2015 are projections.}

\section{9: INTERNATIONAL}

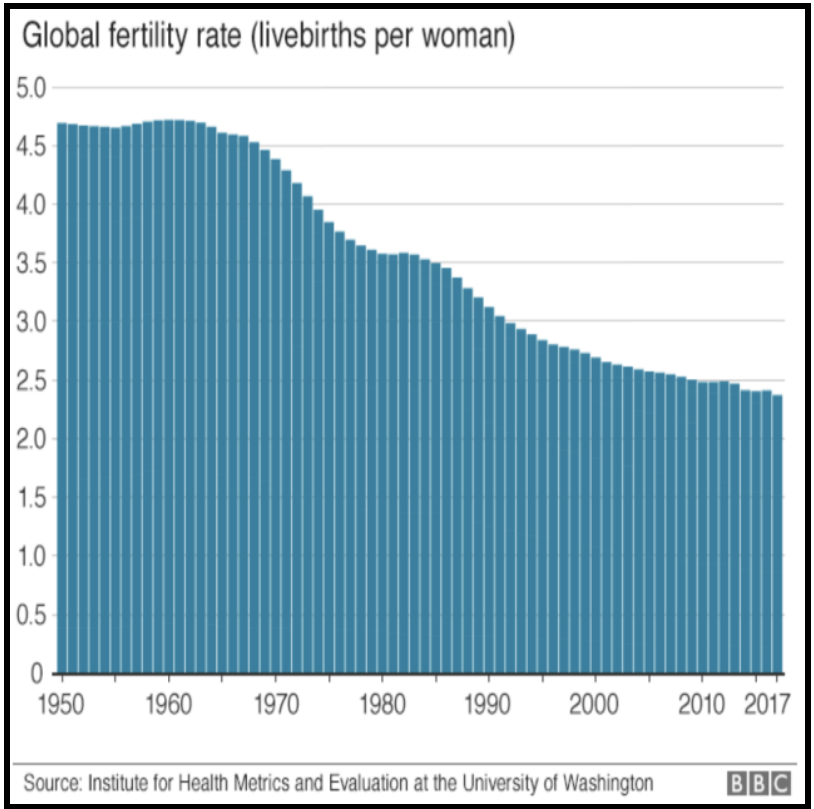

These demographic drivers are a result of improved healthcare (lower child mortality rates, greater access to contraception and more effective disease prevention and treatment) and a shift in socio-economic trends (healthier lifestyles, increased education and greater participation of women in the workforce).

\section{ECONOMIC CHALLENGES}

An increase in the dependency ratio, due to a decrease in the labour force and increase in the elderly population, can lead to a variety of economic consequences. This decline in the working-age population may result in a shortage of qualified workers, lower productivity, higher labour costs for firms and delayed business expansion. Another possible implication is wage inflation which may have other severe repercussions, including the wage-price spiral.

Due to a narrower tax base, and hence lower tax revenue, the government faces immense fiscal pressure to meet increasing demand for healthcare services and pensions. In fact, pensions are principal sources of income for the elderly, accounting for more than 60 percent of theirincome in countries that are members of the Organisation for Economic Co-operation and Development (OECD) [3]. These unsustainable pension and healthcare commitments often have high fiscal costs which may result in a budget deficit, increased government borrowing, higher debt interest payments for the government and crowding out. In addition, relatively high opportunity costs may be experienced due to a lack offederal funds for other necessary social and economic 
policy objectives such as investment in infrastructure and construction of affordable housing.

Furthermore, population ageing can significantly shift consumption patterns, driving consumer and labour demand. This demographic shift is often associated with growth in health care and other service sectors such as leisure. This change in the composition of consumer expenditure may result in inequality, due to an overwhelming demand for labour and hence higher wages in certain sectors, and a change in global economic dominance as demand for particular export markets grow disproportionately to others.

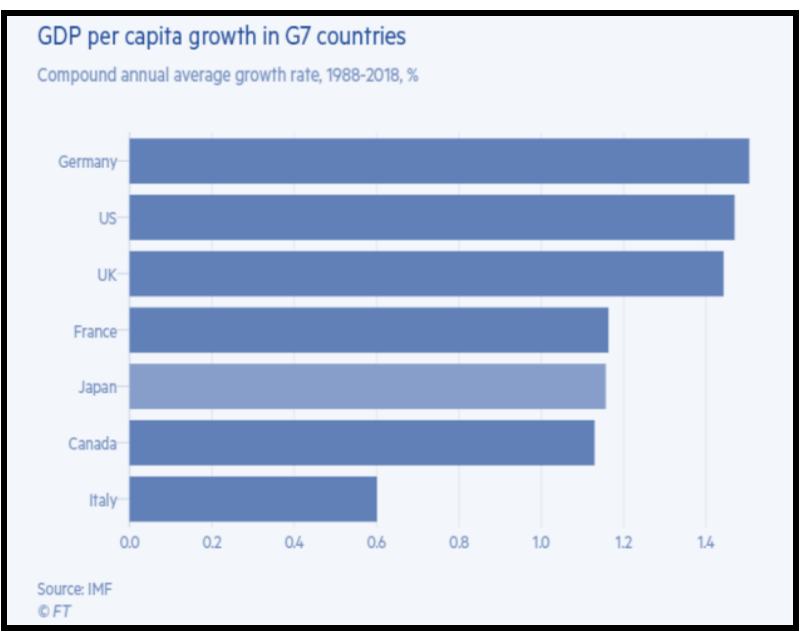

Arapidly ageing populationcoupled with a shrinking labour forcemay hamper economic growth and domestic demand in an economy. According to the IMF, the decline in the share of working age people will probably be a drag on per capita growth between 2020 and 2050. For example, Italy and Japan are not only experiencing relatively low and stagnant economic growth, but also deflationary pressure and low inflation rates, under $2 \%$, which demonstrate lower aggregate demand [4].

Japan

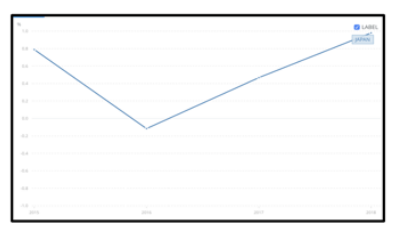

\section{POLICY RECOMMENDATIONS}

There are a variety of policies that may be implemented to offset the shocks to an economy due to population ageing. This paper analyses the effectiveness of several economic policies.

Labour market reforms are crucial policy mechanisms to tackle the crisis of ageing societies. One such reform includes easing immigration laws to encourage an influx of skilled, working-age migrants. Immigration can often reduce the adverse effects of population ageing on economic growth and productivity, by compensating for the decline in the domestic labour force. However, it may be difficult to integrate immigrants into society due the presence of language barriers as well as social and cultural differences. Along with this, dependent family members of immigrant workers may further burden the host government with social security and healthcare needs, which may further deteriorate the economy's condition.

Other schemes intended to reduce the burden on the government include increasing the retirement age [5], reducing incentives for early retirement, tightening eligibility criteria for pensions [5], and decreasing the size of pensionsby adjusting benefit formulas. The aforementioned policies aim to counteract the effects of a shrinking labour force and rapidly ageing population by expanding the workforce and reducing government expenditure on unsustainable pension commitments. On the other hand, these policies may be inefficient and have adverse effects on inequality and poverty in an economy, lowering their standards of living. This is especially the case in physically demanding occupations, where workers may not be able to continue working in old age. In addition, these policies may have high legislative and administrative costs, along with political backlash.

As the working population declines, it is essential to improve productivity to offset the loss of labour input to maintain economic growth levels. An increase in productivity can be achieved by investment in capital and innovation, the advent of new technologies and restructuring of work schedules with a greater number of mandated working hours per day. Referred to as the productivity paradox [6], it is possible that technology may be able to compensate for the loss in productivity due to shifting demographics. While these policies may seem beneficial at first, they too have drawbacks. Such expenditures may not be feasible for some economies already dealing with crippling debt and budget deficits, and productivity boosts due to investments in innovation and technology now, may only be enjoyed in the long-run. Also, longer working hours may discourage and disincentive workers, further contributing to the crisis at hand.

Increasing the labour force participation of women can help reduce labour shortages and mitigate the negative consequences of population ageing [7]. Although the fiscal and administrative costs may be high initially, the overall benefits to the economy outweigh these costs. For example, in Japan, Prime Minister Abe has implemented various policies as a part of 'Womenomics', including encouraging increased provision of child care facilities, promoting flexible work hours, retraining, and easing the rehiring process for women after giving birth. The country has enjoyed benefits from these policies - in the 15-to-64 age group, a record $68.5 \%$ of women held jobs in 2018 [8]. According to research, for a rise of one percentage point in the women's participation rate, the Japanese GDP increases by about half a percentage point [9].

Nudge theory refers to positive reinforcement and designing of consumer choices to encourage decision making 
in the wider positive interests of society, and often serves as the basis for effective economic policies. In the context of population ageing, people could be 'nudged' to save money earlier on to reduce dependence on pensions and decrease the budget burden. For example, in 2018, the UK government implemented a policy mandating employers to automatically enrol workers in a pension scheme [10].

In conclusion, the effectiveness of an economic policy in addressing the issue of population ageing depends on the socio-economic circumstances of the country, as well as the sustainability, feasibility and relative fiscal and opportunity costs of the solution. It is imperative that countries around the world implement policies to boost productivity and economic growth, while also limiting the budget burden in response to the demographic shift of population ageing.

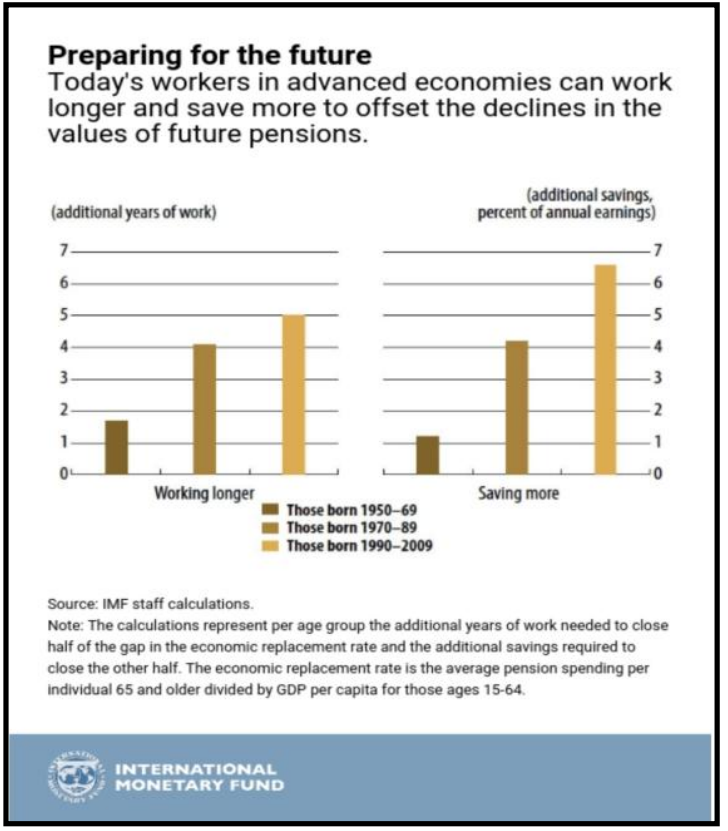

\section{REFERENCES}

[1] "Ageing." United Nations, United Nations, www.un.org/en/sections/issues-depth/ageing/.

[2] "World Population Ageing 2013." United Nations Department of Economic and Social Affairs Population Division, United Nations, 2013.

[3] Soto, Mauricio. "Pension Shock." IMF Blog, 24 Aug. 2017, blogs.imf.org/2017/08/24/pension-shock/.

[4] [4] "Population Ages 65 and above (\% of Total Population)." Data, World Bank,

2017 , www.data.worldbank.org/indicator/SP.POP.65UP.TO.ZS

[5] "Chart of the Week: A Golden Aging for Vietnam?" IMF Blog, 17 July 2017 , www.blogs.imf.org/2017/07/17/chart-of-the-week-a-golden-aging-forvietnam/.

[6] "Productivity, Technology, and Demographics." IMF Blog, 5 May 2017,

www.blogs.imf.org/2017/05/05/productivity-technology-and-demogra phics/.

[7] "Chart of the Week: The Cost of Asia's Aging." IMF Blog, 1 May 2017 , www.blogs.imf.org/2017/05/01/chart-of-the-week-the-cost-of-asias-ag ing/.
[8] Writer, Staff. "Ratio of Working Women Jumps to Record in Japan." Nikkei Asian Review, Nikkei Asian Review, 14 July 2018, asia.nikkei.com/Economy/Ratio-of-working-women-jumps-to-record-i n-Japan.

[9] Fujita, Akiko, and Saheli Roy Choudhury. "Japan's 'Womenomics' Plans Are Driving Change in the Country." $C N B C$, CNBC, 2 Apr. 2018 , www.cnbc.com/2018/04/02/working-in-japan-investing-in-women-co uld-boost-economic-growth.html.

[10] "Increase of Automatic Enrolment Contributions." Increase of Automatic Enrolment Contributions | The Pensions Regulator, www.thepensionsregulator.gov.uk/en/employers/increase-of-automati c-enrolment-contributions. 